\title{
: El diálogo entre tribunales en el marco Europeo
}

\author{
The dialogue between courts \\ in the European framework
}

\author{
TERESA FREIXES \\ Catedrática emérita de Derecho \\ Constitucional. Universitat Autònoma \\ de Barcelona. \\ teresa.freixes@gmail.com \\ https://doi.org/10.7203/cc.1.19053 \\ Fecha de recepción: 11/06/2020 \\ Fecha de aceptación: 25/11/2020
}

\section{Resumen}

En este trabajo se aborda la interacción entre jurisdicciones situadas en distintos niveles, desde la perspectiva de poder delimitar influencias entre ellas en un sistema jurídico multinivel. Se analizan las distintas jurisdicciones, internas, internacionales y supranacionales, así como los procedimientos a través de los cuales se efectúa ese diálogo. Especialmente se pone atención en las relaciones, bilaterales y multilaterales entre los Tribunales Constitucionales, el Tribunal Europeo de Derechos Humanos y el Tribunal de Justicia de la Unión Europea. Y se señalan algunas de las disfunciones existentes al mismo tiempo que se proponen también algunas reformas dirigidas a reforzar y mejorar el diálogo multinivel entre las distintas jurisdicciones.

\section{Palabras clave}

Sistema jurídico multinivel; diálogo entre tribunales; Tribunal Constitucional; Tribunal Europeo de Derechos Humanos; Tribunal de Justicia de la Unión Europea; cuestión de inconstitucionalidad; cuestión prejudicial; consultas interjurisdiccionales.

\begin{abstract}
This work addresses the interaction between jurisdictions located at different levels, from the perspective of being able to define influences between them in a multilevel legal system. Are analyzed the different jurisdictions, internal, international and supranational, as well as the procedures through which this dialogue is carried out. Special attention is paid to the bilateral and multilateral relations between the Constitutional Courts, the European Court of Human Rights and the Court of Justice of the European Union. And some of the existing dysfunctions are pointed out at the same time that some reforms are also proposed aimed at strengthening and improving multilevel dialogue between the different jurisdictions.
\end{abstract}

\section{Keywords}

Multi-level legal system; dialogue between courts; Constitutional Court; European Court of Human Rights; Court of Justice of the European Union; questioning of unconstitutionality; preliminary ruling; inter-jurisdictional consultations. 


\section{Introducción. - II. El sistema multinivel de derechos funda- mentales en la base del diálogo entre tribunales: Indicadores interpretativos. - III. Los efectos del "diálogo" con el Tribunal Europeo de Derechos Humanos. - IV. Los efectos del "diálogo" con el Tribunal de Justicia de la Unión Europea. - V. El incipiente "diálogo" entre el Tribunal Europeo de Derechos Humanos y el Tribunal de Justicia de la Unión Europea. Bibliografía.}

\section{Introducción}

Hablar de "diálogo entre tribunales" es consecuencia directa del sistema jurídico multinivel en el que se sitúa nuestro ordenamiento. Y, como a los tribunales se acude en defensa de derechos e intereses legítimos, es el sistema multinivel de derechos, proyectado en el derecho a la tutela judicial efectiva, el que sirve de canalización a ese "diálogo".

¿Cómo se ha originado ese sistema multinivel de derechos? Ese sistema multinivel de derechos deriva directamente, en sentido "ascendente" de nuestra incorporación a organizaciones internacionales (el Consejo de Europa especialmente, pero no en exclusiva, puesto que Naciones Unidas tiene también una ingente regulación sobre ello) y a organizaciones supranacionales como la Unión Europea (UE). En sentido "descendente", el sistema multinivel tiene en cuenta los derechos regulados en los Estatutos de Autonomía.

Todos estos niveles de protección de derechos cuentan con tribunales y con procedimientos que constituyen órganos de delimitación y garantía, ya se trate de tribunales internos o de tribunales internacionales o supranacionales. Y como un mismo hecho puede, sucesiva o simultáneamente, según los casos, ser objeto de reclamación ante distintos niveles jurisdiccionales, ello se considera como un "diálogo" entre tribunales efectivamente porque, de lo que ellos sentencian, se desprenden máximas interpretativas y/o ejecutivas (en el sentido de ejecución de las sentencias) que sólo cobran sentido en el ámbito de ese multinivel jurídico, sujeto a reglas de jerarquía, competencia y primacía, cuya interpretación de conjunto es lo que otorga coherencia al sistema.

Pero antes de entrar en el tema, se hace necesario precisar algo la noción de "diálogo" para referirla a lo que pueda suceder entre altos tribunales, en distintos niveles, porque este concepto puede ser empleado de formas muy diferentes. Así, a veces, se habla de "diálogo" cuando únicamente se da la circunstancia de que un tribunal cita a otro; otras veces lo que se examinan son las influencias recíprocas entre dos o más tribunales; y también puede usarse el "diálogo" en el sentido de interacción explícita. Dejando de lado el tema de simple cita, voy a considerar que el denominado "diálogo", que no deriva de otra cosa que del cumplimiento de las funciones propias de cada jurisdicción, se producirá tanto cuando se observen influencias recíprocas por hacerse eco un tribunal de las construcciones interpretativas de otro, como si de lo que se 
trata es de la influencia explícita y/o reenvío de las construcciones interpretativas de un tribunal sobre o hacia otro. No incluiré, pues, aquí, lo que algunos denominan "espacio cultural común" de orden jurisdiccional, puesto que lo que voy a entender como "diálogo", es la interacción entre jurisdicciones situadas en distintos niveles, desde la perspectiva de poder delimitar influencias entre ellas'. Tampoco entraré a examinar las influencias mutuas que existen entre los tribunales europeos, internos y supranacionales, y otros tribunales que no se sitúan en el marco del sistema multinivel derivado de nuestra incorporación al Consejo de Europa y a la UE. Y no será objeto de este trabajo la denominada cooperación judicial ente tribunales de distintos estados, a pesar de que el tema está realmente presente por ejemplo en el caso de la orden europea de detención y entrega, o la orden de protección a víctimas, pues estimo que, al tratarse de cooperación horizontal, merecen otro tipo de estudio.

\section{El sistema multinivel de derechos fundamentales en la base del diálogo entre tribunales: Indicadores interpretativos}

Varios son los niveles jurisdiccionales del "diálogo" y las vías procedimentales que lo instrumentan. Podemos considerar, por una parte, a los órganos jurisdiccionales y, por otra parte, a los procedimientos propios de la actuación en cada jurisdicción.

Respecto de los órganos jurisdiccionales, es necesario distinguir entre:

- Tribunales internos -Poder Judicial y Tribunal Constitucional (TC)-, mediante las apelaciones y los recursos de casación y revisión, cuando proceden, ante superiores jerárquicos y/o el Tribunal Supremo (TS) y, por otra parte, el recurso de amparo relativo al art. 24 CE sobre el derecho a la tutela judicial efectiva y la cuestión de inconstitucionalidad presentada por los jueces ordinarios al TC cuando consideran que la ley aplicable al caso puede ser contraria a la Constitución.

- Tribunal Europeo de Derechos Humanos (TEDH): cuando se interpone una demanda contra España fundamentada en los artículos que reconocen derechos procesales (acceso a los recursos, juicio equitativo, garantías procesales). El "diálogo" existe porque es necesario agotar los recursos internos (amparo ante el TC incluido, si se trata de un derecho que tiene acceso a este recurso) antes de presentar la demanda al TEDH y porque España, al haber reconocido la jurisdicción del TEDH, está obligada a ejecutar las sentencias dictadas por éste.

- Tribunal de Justicia de la Unión Europea (TJUE): en este caso el "diálogo" se encauza mediante la presentación, por parte del juez español que está juzgando un asunto, de una cuestión prejudicial ante el TJUE, para dilucidar si la norma española que se tiene que aplicar al caso controvertido, es contraria o no al Derecho de la UE.

Las vías procedimentales aludidas, el segundo nivel de indicadores, constituyen vías de "diálogo" entre las diversas cortes:

- En las apelaciones, en el ámbito interno, porque la instancia superior, argumentadamente, manifiesta su conformidad o disconformidad con la inferior,

1 Véase, al respecto, De Vergottini (2011). 
la que ha dictado previamente sentencia. Lo mismo sucede cuando se trata de los recursos de casación y revisión, dirimidos por el TS, que se producen en interés de la ley o por infracción de doctrina legal, así como, en el caso de la revisión, cuando acontecen hechos nuevos tras la sentencia firme anterior, los cuales, de haberse conocido hubieran tenido incidencia en el sentido del fallo.

- En el recurso de amparo, porque con él, desde la perspectiva del "diálogo" se puede verificar, por parte del TC, si los jueces ordinarios han respetado el art. $24 \mathrm{CE}$, es decir, el derecho a la tutela judicial efectiva y las garantías del proceso. De este modo, se aseguran procedimentalmente ante el TC determinados derechos, los que se encuentran regulados en el art. $14 \mathrm{CE}$ y del 15 al 29 CE (el derecho a la objeción de conciencia al servicio militar obligatorio del art. 30.2, que tuvo su función en los primeros años de desarrollo constitucional, ha perdido actualmente su funcionalidad al haberse profesionalizado el ejército). En estos casos, el "diálogo" aparece como un derecho "paraguas" dando cobertura procesal a la correcta defensa de los derechos que tienen acceso a esta garantía. Incluso podríamos conferirle un efecto extensivo cuando la alegación sustantiva se produce sobre las garantías del proceso, es decir, sobre el art. $24 \mathrm{CE}$ en tanto que tal, pues en estos casos, se estaría "dialogando", indirectamente, sobre los derechos e intereses legítimos que se han alegado ante los jueces ordinarios.

- En la cuestión de inconstitucionalidad se pretende asegurar que las leyes que se aplican en los juicios son constitucionales, más allá de que haya transcurrido el plazo de 3 meses que la Constitución otorga a una serie de órganos legitimados para interponer un recurso de inconstitucionalidad contra la ley. Como bien puede darse el caso de aprobarse una ley que no ha sido recurrida, pero que en su aplicación aparecen, en un caso abierto, sobre cualquier materia, ante cualquier tribunal ordinario, dudas acerca de su constitucionalidad, la Constitución ha previsto esta forma de "diálogo" para asegurar que la duda quede disipada. En estos casos, el proceso "a quo" queda suspendido a la espera de que el TC se pronuncie, aunque, en general, la ley puede seguir siendo aplicada, salvo que, al hacerse pública la presentación de la cuestión ante el TC, otros jueces que tengan causas abiertas en la que se tendría que aplicar tal ley, suspendan también en auto motivado el pleito y lo comuniquen al propio TC, al Consejo General del Poder Judicial y a los interesados. De este modo, el "diálogo" condiciona la resolución no sólo del proceso que lo ha originado sino también a procesos conexos, debido a que es la misma ley cuestionada la que sería decisiva para resolver el caso. Los jueces "a quo" sólo pueden resolver el caso teniendo en cuenta lo que haya decidido el TC: podrán aplicar la ley si éste la considera constitucional y no podrán hacerlo y deberán buscar la respuesta en el resto del ordenamiento jurídico si lo que el TC ha constatado es que la ley cuestionada vulnera el orden constitucional.

- En los procesos ante el TEDH, el "diálogo" tiene lugar cuando la sentencia de la Corte de Estrasburgo constata que los jueces internos no han garantizado en forma correcta los derechos reconocidos en el Convenio Europeo de Derechos Humanos (CEDH) y los Protocolos adicionales al mismo². La sentencia de Estrasburgo, de la Sala que la haya pronunciado o de la Gran Sala si el estado ha apelado, deberá ser ejecutada por los jueces internos, concretamente, mediante la interposición de un recurso de revisión ante el

2 Véase Ripoll Carulla (2007); Ruiz Miguel (1998); Pérez Sola (2015). 
TS. Ello es así porque sólo se puede acudir ante el TEDH tras el agotamiento de los recursos internos (amparo incluido si se trata de un derecho susceptible de ser recurrido en esta vía ante el TC), lo cual implica la existencia de sentencia firme. La sentencia del TEHD constituye un hecho nuevo, a la luz del recurso de revisión, que ha de ser necesariamente tenido en cuenta, ya que de haberse producido anteriormente, ello hubiera sido decisivo para la emisión de la sentencia firme. Nótese que, en este caso, están implicados todos los tribunales internos: el de instancia, el de apelación, TS en casación/ revisión en su caso y el TC en recurso de amparo si procede, y todo ello en la fase previa a acudir al Tribunal de Estrasburgo. Tras el fallo del TEDH, vuelve a ser el TS y, en dependencia de lo que éste decida en la sentencia de revisión, los otros tribunales implicados en el asunto. Se trata, pues, en este caso, de un "diálogo" ascendente y descendente, de ida y vuelta, entre los tribunales internos y la jurisdicción internacional europea.

- En relación con el TJUE, la cuestión prejudicial es quien mejor representa el "diálogo" entre el juez interno y el juez comunitario. Es el juez interno quien decide, de oficio o a instancia de parte la presentación de la cuestión, pero es de obligada presentación cuando la duda acerca de la compatibilidad entre norma interna y norma comunitaria es alegada ante un tribunal interno que deba dictar sentencia firme, ya que la primacía del Derecho de la Unión no puede permitir que obtengan firmeza las resoluciones judiciales que sean contrarias a éste. La presentación de la cuestión prejudicial, del mismo modo que la cuestión de inconstitucionalidad, suspende el pleito a quo, hasta que el TJUE se haya pronunciado y es obligatorio seguir el sentido de su fallo.

- Y también cabría hacer una alusión al "diálogo" entre el TEDH y el TJUE, puesto que en ocasiones cualquiera de los dos tribunales tiene en cuenta la jurisprudencia sentada por el otro en sus fundamentos jurídicos.

\section{Los efectos del "diálogo" con el Tribunal Europeo de Derechos Humanos}

Respecto de las indicaciones al legislador, señalaré únicamente algunos ejemplos, desde una doble perspectiva. El análisis de estos casos indica que en ocasiones lo que realiza el TEDH es precisar indicadores o cánones concretos y precisos que tendría que seguir la legislación nacional y que, normalmente, van seguidos de una reforma adaptativa de la misma. En otros asuntos, sin embargo, no son los casos concretos contra el Estado que adapta sus normas quienes han influido directamente en los cambios, sino que es el conjunto de la jurisprudencia del TEDH o, de algún grupo de sentencias, especialmente casos recientes, los que, sin que se dirijan singularmente al Estado que cambia su legislación, se constata que es tal jurisprudencia la que ha impulsado los cambios. Pondremos unos ejemplos:

- Establecimiento de líneas o cánones precisos a seguir para que la legislación nacional no esté enfrentada al CEDH o a la jurisprudencia del TEDH. En la mayor parte de los casos, se trata de precisiones que debería incorporar la legislación nacional para evitar que el Convenio fuera vulnerado en casos concretos. Así, por ejemplo, el Caso Hutten-Czapska contra Polonia ${ }^{3}$ o el Caso Messina contra Italia ${ }^{4}$, cuando el TEDH sugirió la reforma de la legislación

3 Caso Hutten-Czapska contra Polonia. STEDH de 22 de febrero de 2005.

4 Caso Messina contra Italia. STEDH de 10 de noviembre de 2004. 
interna para adecuarla al Convenio. También aquí, en España, varias reformas internas, especialmente en las leyes de procedimiento, se han venido realizando para reforzar específicamente las garantías de los derechos; por ejemplo, desde el Caso Prado Bugallo ${ }^{5}$, se venía insistiendo en las garantías con que tenían que contar las intervenciones de las comunicaciones telefónicas.

- Influencia doctrinal sobre el legislador derivada de asuntos que no conciernen al país contra el que se han dictado las sentencias. Actualmente, ha sido muy relevante el eco que han tenido en España las sentencias a los Casos Basic contra Croacia ${ }^{6}$, Cevat y Özel contra Turquía ${ }^{7}$ y Versini-Campinchi y Crasnianski contra Francia ${ }^{8}$, que han merecido un estudio de la Secretaría Técnica de la Fiscalía General del Estado, en la que se evalúa la conformidad de las reformas legislativas habidas en España con la jurisprudencia sentada por el TEDH en tales sentencias. También la STEDH, dictada en Gran Sala ${ }^{9}$, N.D. y N.T. contra España, en la que, cambiando su jurisprudencia anterior (lo cual va a originar un cambio de jurisprudencia interna) el TEDH considera que las denominadas "expulsiones en caliente" no vulneran el Convenio ${ }^{10}$.

También cabe señalar el reconocimiento explícito que algunas veces se ha realizado del control de convencionalidad por parte de los órganos de control constitucional. En nuestro caso, desde sus primeras sentencias, el TC se ha hecho eco de las del TEDH ${ }^{11}$, especialmente en la aplicación de los escrutinios o "test" a partir de los cuales se delimitan elementos configuradores de los derechos fundamentales o se configuran mecanismos de interpretación de los mismos. También otros órganos de control de constitucionalidad, como el Consejo Constitucional francés o la Corte Constitucional italiana, además, aunque con matices, del Tribunal Constitucional Federal de Alemania.

- En España, cabe destacar que, en la mayor parte de las veces, lo que ha hecho el TC es fijarse en la interpretación del TEDH y señalarlo explícitamente las primeras veces que, sobre un derecho o un elemento configurador concreto sobre el derecho, ha utilizado la jurisprudencia europea, pasando, a continuación y en las siguientes sentencias, a autocitarse, sin desvelar ya el origen de la construcción interpretativa. Ello puede apreciarse en varios casos, dentro de los cuales señalaré el escrutinio sobre la igualdad reconocida por el art. $14 \mathrm{CEDH}$, fundamentado en la versión francesa del mismo, que es la que el TEDH reconoce como auténtica al respecto desde el Caso sobre el régimen de la lengua en la enseñanza en Bélgica ${ }^{12}$, exigiendo que se trate de dos supuestos comparables, que exista una diferencia de trato compatible con la sociedad democrática para cumplir objetivos legítimos y que la diferencia no sea desproporcionada; posteriormente se

Caso Prado Bugallo contra España. STEDH de 18 de febrero de 2003.

Caso Basic contra Croacia. STEDH de 25 de octubre de 2016.

Caso Cevat y Özel contra Turquía. STEDH de 7 de junio de 2016.

8 Caso Versini-Campinchi y Crasnianski contra Francia. STEDH de 16 de junio de 2016.

9 Normalmente las sentencias del TEDH son dictadas en Sala, pero la sentencia de la Sala puede ser recurrida ante la Gran Sala, como ha sucedido en este caso, por parte del Gobierno de España. La sentencia de la Gran Sala es definitiva y no es posible ulterior recurso contra ella.

10 Caso N.D. y N.T. contra España. STEDH del 13 de febrero de 2020.

11 El antiguo Presidente del TC, Dr. Pérez de los Cobos, resaltó esta interrelación en la conferencia que impartió con motivo de la visita del Presidente del TEDH a España el 22 de mayo de 2015.

12 Caso Régimen de la lengua en la enseñanza en Bélgica. STEDH de 23 de julio de 1968. 
repite este razonamiento en todas las sentencias dictadas por el Tribunal de Estrasburgo, habiendo pasado también a ser utilizado por nuestro TC. Al principio, por ejemplo, en su primera sentencia en materia de igualdad, un caso de aplicación de la legislación laboral (STC 22/1981, de 2 de julio), cita expresamente al TEDH. Con posterioridad, en la mayor parte de los casos, el TC remite a su propia jurisprudencia, que está basada en la del TEDH, pero sin manifestarlo explícitamente. Podríamos realizar una apreciación similar en cuanto al test de los límites que el Convenio permite establecer sobre ciertos derechos, cuya interpretación de conjunto por parte del TEDH crea también una estructura interpretativa muy semejante a la de la igualdad; o al escrutinio que debe ser realizado para apreciar la existencia o no de dilaciones indebidas en los procesos, el principio de proporcionalidad o el criterio de razonabilidad, por poner varios ejemplos. En todos ellos, el TC, al amparo del art. 10.2 CE ha afirmado reiteradamente ${ }^{13}$ que, de conformidad con lo dispuesto en el art. 10.2 de nuestra Constitución, “la jurisprudencia del Tribunal Europeo de Derechos Humanos (...), no sólo ha de servir de criterio interpretativo en la aplicación de los preceptos constitucionales tuteladores de los derechos fundamentales", sino que también "resulta de aplicación inmediata en nuestro ordenamiento". De ahí que se la tenga en cuenta sistemáticamente y cada vez más en la jurisprudencia interna, con esta doble dimensión: interpretativa en general y de aplicación inmediata al caso concreto.

- En Francia, el control de convencionalidad es configurado por el Consejo Constitucional como subsidiario del que tienen que realizar los jueces ordinarios, si bien en la Decisión 2004-505 que podemos considerar como "caso piloto", lo consideró incardinado en la tradición constitucional francesa ${ }^{14}$. Se trataba de una Decisión en la que el Consejo Constitucional aplicó el sistema multinivel de derechos fundamentales pues, además del CEDH y la jurisprudencia de Estrasburgo, tuvo en cuenta los Tratados de la UE y la Carta de los Derechos Fundamentales de la UE, para realizar la interpretación del propio sistema francés en un caso complejo, relativo a los efectos de la laicidad proclamada por la Constitución.

- En Italia, la Corte Constitucional también se adjudicó un control directo sobre la convencionalidad, salvaguardando el control ejercido por los tribunales ordinarios. Fue en las Sentencias 348 y 349, de 2007, derivadas de la interposición de sendas cuestiones de legitimidad constitucional (equivalentes a nuestras cuestiones de inconstitucionalidad). En ambos caso, relativos al derecho a la propiedad en relación con el derecho al debido proceso, distinguiendo además, entre el valor del CEDH y el Derecho de la UE en el marco constitucional italiano, la jurisprudencia de Estrasburgo cobra un valor interpretativo que la incluye en el ámbito de la determinación del canon de constitucionalidad, autootorgándose la Corte competencia directa al respecto.

- En Alemania, con un sistema jurídico que otorga al Convenio valor de ley, éste se integra como canon interpretativo, puesto que la Constitución dispone que los tribunales dictarán las sentencias conforme "a la ley y al Derecho" (art. 20.3 de la Constitución de Alemania). En cuanto a los efectos internos de las sentencias del TEDH, el Tribunal Constitucional Federal de Alemania distingue si se trata de un asunto de ámbito privado o público. En los asuntos

13 Por todas, la STC 303/1993, de 25 de octubre.

14 Decisión del Consejo Constitucional francés 2004-505, de 19 de noviembre de 2004. 
de ámbito privado ${ }^{15}$ el TC alemán considera que debe dejarse a la voluntad de las partes el cómo ha de darse cumplimiento a la sentencia del TEDH. En los asuntos no privados, sometidos al Derecho civil o penal, se puede solicitar la revisión de la sentencia firme interna que provocó la demanda ante el TEDH, de forma similar a la actual legislación vigente en España ${ }^{16}$.

Si tenemos en cuenta que Alemania, y España, son los dos países europeos cuya legislación interna prevé el recurso de amparo ante el TC, para proteger los derechos fundamentales, que es necesario utilizar antes de acudir al TEDH para agotar los recursos internos, cabe preguntarse si es precisamente la existencia de tal recurso lo que hace que tanto Alemania como España aparezcan, en las estadísticas del TEDH, entre los estados menos condenados por este Tribunal.

Alemania, miembro fundador del Consejo de Europa, ha sido objeto, entre 1958 y 2016, de unas 600 demandas ante el TEDH y la mayor parte de ellas no tuvieron resultado condenatorio siendo el objeto principal de las mismas el art. 6 CEDH relativo a las garantías procesales. La web del TEDH informa que el número total de condenas ha sido de 321, que otorga una de las ratios anuales más baja, teniendo en cuenta los años que Alemania lleva siendo parte del Convenio.

España, adherida al CEDH y reconociendo la jurisdicción del TEDH en 1979, ha sido condenada un total de 103 veces por el TEDH (no consta, en la web del Consejo de Europa, el número de demandas tramitadas) desde que se emitió la primera sentencia en 1988. El número de sentencias emitidas ha sido de 157, según la web del propio Tribunal. El art. $6 \mathrm{CEDH}$ ha constituido también el centro de atención de las demandas.

Véanse, al respecto, las siguientes tablas, que provienen de la web del propio TEDH:

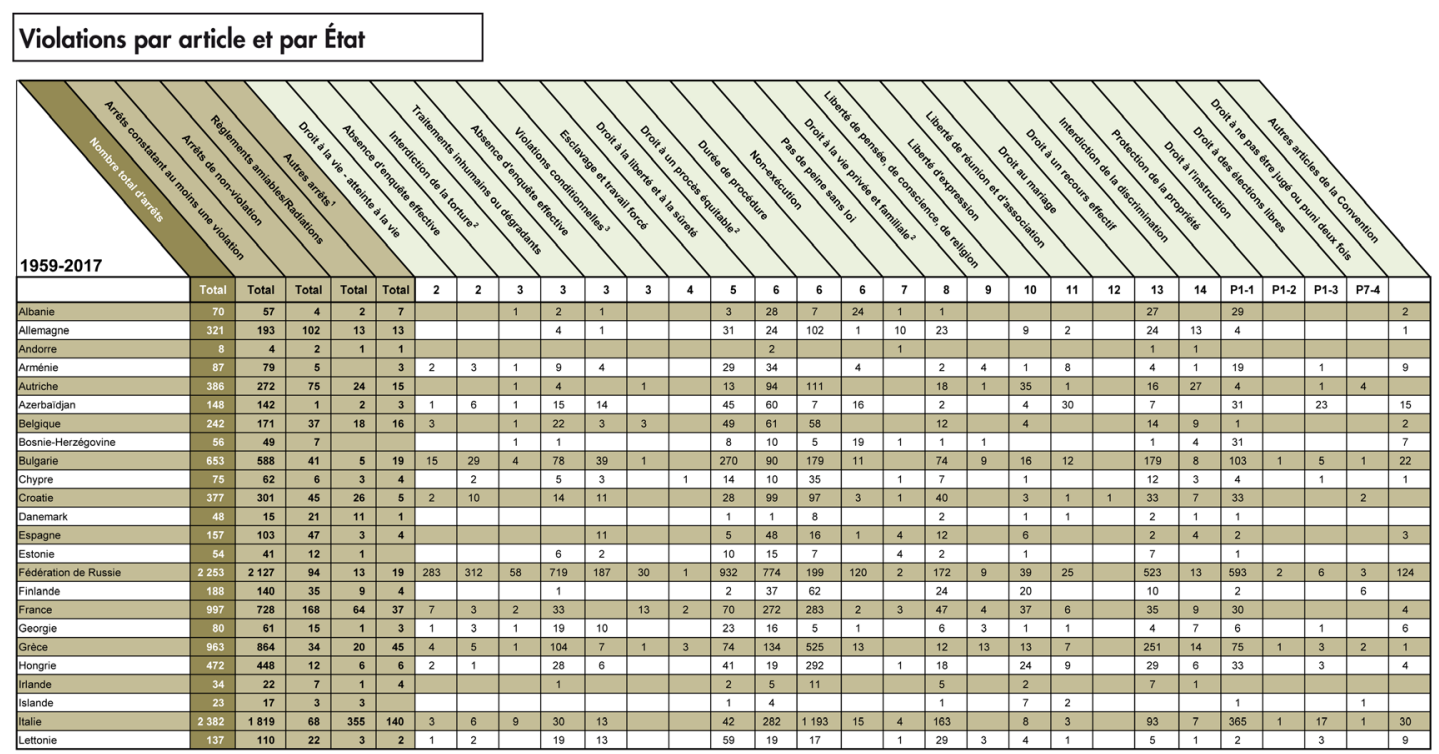




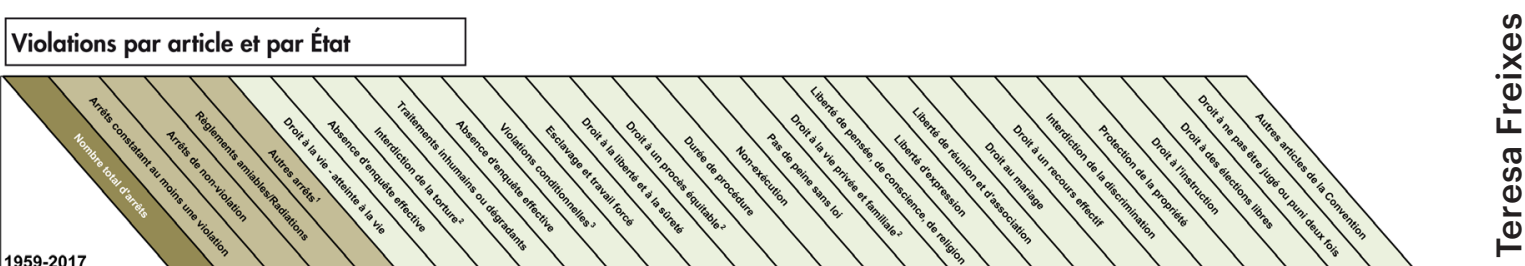

\section{Los efectos del "diálogo" con el Tribunal de Justicia de la Unión Europea}

Tal como he afirmado, la forma habitual de "diálogo" entre tribunales nacionales y el Tribunal de Justicia de la UE se realiza mediante la presentación de una cuestión prejudicial. Durante los primeros años de pertenencia a la UE, los tribunales españoles fueron parcos en la presentación de cuestiones prejudiciales, especialmente el TS y el TC. Tan parcos que, en la primera década del presente siglo, en varias ocasiones se planteó la posibilidad de que, ante la negativa de los altos tribunales a presentar la cuestión prejudicial aun cuando la sentencia que fueran a emitir tuviera firmeza, la Comisión planteara un recurso de incumplimiento contra España al respecto. De ahí que considere que el inicio del "diálogo" entre los sistemas jurídico-constitucionales internos y el sistema de la UE se sitúe en la primera vez en que los Tribunales Constitucionales de los Estados miembros de la UE presentaron una cuestión prejudicial ante el Tribunal de Justicia. Ello es así, a mi entender, porque la presentación de esta primera cuestión cierra el círculo del diálogo entre tribunales ordinarios, Tribunales Constitucionales y Tribunal de Justicia. Hasta que los Tribunales Constitucionales no entraran a enjuiciar directamente la compatibilidad entre el Derecho interno y el Derecho de la Unión, no se produjo, en mi opinión, una verdadera integración jurídica europea, puesto que la evasión que realizaban los Tribunales Constitucionales al respecto, abría brechas centrífugas que la primacía del Derecho de la UE no podía soportar si verdaderamente se trataba de una Unión jurídicamente integrada.

En efecto, el art. 267 del Tratado de Funcionamiento de la Unión Europea obliga a la presentación de la cuestión prejudicial, a solicitud de parte, cuando la decisión que deba tomar el tribunal interno no sea susceptible de ulterior recurso, obligación que entra dentro de la lógica de impedir que cobre firmeza una sentencia interna contraria al Derecho de la UE. Y hay que destacar también, con carácter previo, que hay asuntos que requieren una cierta rapidez en la resolución de la cuestión, puesto que se trata de temas "sensibles" como pueden 
ser el asilo, el control de fronteras o, entre otros, la sustracción de menores, para los que está previsto un procedimiento prejudicial de urgencia.

También podemos señalar que, actualmente, los Estados que más cuestiones prejudiciales plantean no tienen características comunes. Ni son los grandes ni los pequeños, es decir, que parece que lo importante no es la cantidad de población ni el nivel de litigiosidad, sino que son otros factores los que deben ser tenidos en cuenta. Así, de un total de 453 asuntos prejudiciales, la información que el TJUE proporciona es la siguiente ${ }^{17}$ :

\begin{tabular}{l|l}
\hline Estado (en 2016) & Asuntos iniciados \\
\hline Alemania & 84 \\
\hline Italia & 62 \\
\hline España & 47 \\
\hline Países Bajos & 26 \\
\hline Bélgica & 26 \\
\hline
\end{tabular}

Por otra parte, hay que señalar también que, en su misión de "guardiana de los Tratados", la Comisión Europea realiza también el seguimiento de las cuestiones prejudiciales en las que el Tribunal constata que el Derecho interno no es concorde con el Derecho de la Unión.

Realizaré, en este punto, algunas consideraciones, acerca de las cuestiones prejudiciales presentadas por España y algunos otros países de la UE, en el marco de ese "diálogo" dirigido a dar coherencia al multinivel jurídico entre el Derecho de la Unión y el Derecho interno.

- En España, el TC presentó su primera, y única hasta el momento presente, cuestión prejudicial en $2011^{18}$, interpuesta en el marco de un recurso de amparo contra un Auto de la Sala Primera de la Audiencia Nacional en materia de aplicación de la orden europea de detención y entrega a un ciudadano italiano, el Asunto Melloni, condenado en rebeldía en su país por un delito de quiebra fraudulenta ${ }^{19}$. Ello implica que el TC se declara competente para analizar las garantías del debido proceso en relación con la evolución del Derecho de la UE, cosa que hasta el momento había sido preterida. Se declara, en consecuencia, la trascendencia constitucional del Derecho de la Unión y se analiza si éste ha de incorporarse al canon de constitucionalidad ${ }^{20}$. Para ello, el TC utiliza, si bien tangencialmente, la jurisprudencia del TEDH sobre el debido proceso y se plantea si el art. 53 de la Carta de los Derechos Fundamentales otorga a ésta carácter subsidiario, o si constituye un instrumento federal uniformador o si ha de entenderse como una cláusula de estándar mínimo ${ }^{21}$. Hasta ese momento se consideraba que, al estar el Derecho comunitario integrado en el Derecho interno, era al juez ordinario y no al TC a quien correspondía resolver el conflicto entre normas, si bien existió una cierta polémica al respecto, sobre todo alrededor de si el Derecho de la UE debía integrarse en el canon de constitucionalidad; ello llevó a considerar

17 Véase la información sobre las cifras clave de la actividad judicial del TJUE en el Informe Anual 2016. Panorámica del año. Accesible en la web del TJUE: https://curia.europa.eu/jcms/upload/ docs/application/pdf/2017-04/ti_pubpdf_qdaq17001esn_pdfweb_20170424120212.pdf.

18 Auto 86/2011, de 9 de junio de 2011.

19 Véase Aguilar Calahorro (2011).

20 Véase Macías Castaño (2014).

21 Un análisis en profundidad del Auto en Arroyo Jiménez (2011). 
que la negativa de un juez ordinario a interponer la cuestión prejudicial podía ser objeto de recurso de amparo ante el $\mathrm{TC}^{22}$. En la estadística proporcionada por el Consejo General del Poder Judicial, se puede apreciar la progresión de la presentación de cuestiones prejudiciales en España. Nótese, por una parte, el escaso porcentaje que estas cuestiones representan en el conjunto de las presentadas al TJUE por parte de los Estados miembros de la UE. Por otra parte, hay que señalar también que, en los últimos años, son el TS y los Tribunales Superiores de Justicia (éstos en su conjunto) quienes más cuestiones presentan, aunque escasas en número ${ }^{23}$.

Cabe destacar también la cuestión prejudicial presentada por el TS, mediante el auto de 1 de julio de $2019^{24}$, en relación con la adquisición de la condición de diputado europeo por parte de un condenado por sentencia firme a inhabilitación para ejercicio de cargo público al tiempo que se le condenaba también por los delitos de sedición y malversación de fondos públicos ${ }^{25}$. El TJUE realizó en su sentencia, Asunto C-502/1926, un cambio de jurisprudencia que va a afectar a muchos de los Estados miembros de la UE, al considerar que una persona elegida como miembro del Parlamento Europeo, adquiere la condición de diputado europeo, con todos los derechos, desde el momento de su elección. Con anterioridad, la jurisprudencia del TJUE remitía a la aplicación de los requisitos exigidos por la legislación interna, notablemente la promesa o juramento del orden constitucional aunque se podían exigir otros condicionantes. Ello ha afectado ya a otros hechos ${ }^{27}$, que han sido dirimidos por el Parlamento Europeo teniendo en cuenta la nueva jurisprudencia del TJUE.

- La literatura jurídica sobre la cuestión prejudicial en Alemania es abundante, quizás debido a que Alemania es el Estado miembro de la UE en el que los jueces plantean un mayor número de cuestiones prejudiciales. Una premisa a tener en cuenta es la posición que el TC federal atribuye al Derecho de la Unión en el ordenamiento constitucional de Alemania, pues la interpretación realizada por éste respecto de cómo opera el principio de primacía del Derecho de la UE respecto de la Constitución constituye la clave de bóveda

22 Véase Baño León (2004).

23 Fuente de la estadística: http://www.poderjudicial.es/cgpj/es/Temas/Estadistica-Judicial/ Estadistica-por-temas/Aspectos-internacionales/

Cuestiones-prejudiciales-ante-el-Tribunal-de-Justicia-de-las-C-E-/.

24 Auto Causa especial 20907/2017, de 19 de diciembre de 2019.

25 En puridad no era necesario presentar tal cuestión prejudicial, puesto que la legislación europea vigente había sido interpretada derivando al cumplimiento del Derecho interno en forma reiterada, siendo esta interpretación la tenida en cuenta en la sentencia firme emitida por el TS español, por lo que no existía duda entre la compatibilidad del Derecho interno con el de la UE. Pero la parte condenada en la sentencia interna solicitó la presentación de la cuestión en el recurso de súplica y el TS entendió que debía presentarla, seguramente creyendo al mismo tiempo que el TJUE reforzaría la posición interna. Ello no sucedió así, sino al contrario, lo que obliga a tener en cuenta la nueva posición del TJUE en los casos que se puedan dar en el futuro, no sólo en España, sino en el conjunto de los Estados miembros de la UE.

26 Asunto C-502/19. STJUE, dictada por la Gran Sala el 19 de diciembre de 2019.

27 Me refiero a la adquisición de la condición de diputados europeos de los políticos catalanes prófugos de la justicia, que no han podido ser juzgados en España porque la legislación en vigor impide los juicios en ausencia (España no ha transpuesto la Directiva (UE) 2016/343 del Parlamento Europeo y del Consejo de 9 de marzo de 2016, por la que se refuerzan en el proceso penal determinados aspectos de la presunción de inocencia y el derecho a estar presente en el juicio) y el Parlamento Europeo, al no haber sido juzgados ni, por ello, condenados, les ha otorgado la condición de diputados europeos por el simple hecho de su elección, obligando a que las autoridades internas españolas, conforme a la legislación europea, tenga que obtener el suplicatorio del Parlamento Europeo para conseguir su entrega a España a los efectos procesales oportunos. 
para entender los registros que el constitucionalismo alemán, y otros influenciados por éste, atribuyen al "diálogo" entre el Tribunal Constitucional federal y el TJUE, sobre todo tras la proclamación de la Carta de los Derechos Fundamentales de la UE y el control de constitucional que el TC alemán realizó respecto de la fallida Constitución Europea, reiterado todo ello con la entrada en vigor del Tratado de Lisboa. En efecto, la primera cuestión prejudicial se presentó al TJUE por parte del TC alemán, en 2014, en relación con las denominadas OMT (compra de obligaciones de los Estados miembros por parte del Banco Central Europeo en los mercados secundarios de deuda ${ }^{28}$; esta facultad fue cuestionada por el TC federal como contraria a la Constitución de Alemania y el TJUE sostuvo la conformidad con el Derecho de la UE remitiendo al TC alemán lo principal del litigio, alargando el "diálogo" entre ambas cortes ${ }^{29}$ hasta que, el 16 de junio de 2015, el TJUE dictó la correspondiente sentencia ${ }^{30}$.

- El Consejo Constitucional de Francia plantea la primera cuestión prejudicial al TJUE en $2013^{31}$. Francia ha sido también reticente al uso de este instrumento de "diálogo" entre tribunales por parte de su órgano del control de la constitucionalidad, pues en 1975 declinó la presentación de una cuestión prejudicial alegando que no era de su competencia y no abandonó esa posición hasta $2013^{32}$. Se trataba, esta primera cuestión prejudicial, de una pregunta acerca de la orden europea de detención y entrega, planteada en el marco de lo que allí es una cuestión prioritaria de constitucionalidad planteada en este caso ante el Consejo Constitucional por la Cour de Cassation (equivalente a nuestro TS). Ello supuso aceptar el rol jurisdiccional del Consejo Constitucional, como alta instancia resolutiva, no limitada a la estricta función de legislador negativo que tenía antes de haber asumido, él también por su parte, funciones de control "a posteriori" en el marco de las cuestiones prioritarias de constitucionalidad. Por ello, podemos considerar que la presentación de tal cuestión prejudicial, constituye el inicio de un ejemplo de "diálogo" multinivel, entre tres órdenes jurisdiccionales, dos de ellos internos (la Cour de Cassation y el Consejo Constitucional) y otro supranacional (el TJUE).

- Italia también acude por vez primera ante el Tribunal de Justicia de la UE en $2013^{33}$. También en el transcurso de un control de constitucionalidad por vía incidental (equivalente a la cuestión de inconstitucionalidad), la Corte Constitucional Italiana realiza un viraje en su doctrina y abre directamente el "diálogo" entre las dos cortes ${ }^{34}$. Se trataba de la aplicación de la norma italiana que había realizado la transposición de una directiva relativa a las condiciones de trabajo de los enseñantes (profesores interinos) en la función pública. La Corte italiana fundamentó la decisión de presentar la cuestión prejudicial en la imposibilidad objetiva de poder realizar el juicio de adecuación entre la legislación interna y la comunitaria.

El "diálogo, pues, entre juez interno (en el fondo también como juez comunitario) y el Tribunal de Justicia de la UE no se consolida hasta la segunda

28 Auto de 14 de enero de 2014 relativo a cinco procesos acumulados relativos a quejas por inconstitucionalidad. Véase López Castillo (2014).

29 Podemos citar el estudio realizado por García-Andrade Gómez (2014).

30 Véase Sarmiento Ramírez-Escudero (2015).

31 Décision n. ${ }^{\circ}$ 2013-314 QPC du 4 avril 2013.

32 Véase, sobre la evolución de esta cuestión, el trabajo de Droin (2014).

33 Ordinanza del 3 de julio de 2013, n. ${ }^{\circ} 207$.

34 Véase Novi (2014); Guastaferro (2013). 
década del Siglo XXI cuando, entre los años 2013 y 2014, se plantean, en los Estados miembros que he señalado, sendas cuestiones prejudiciales desde los respectivos Tribunales Constitucionales al TJUE. Se trata, pues, de un diálogo que sólo recientemente se ha perfeccionado, pues hasta esos momentos no se establecieron interrelaciones entre los tribunales ordinarios, los Tribunales Constitucionales y el TJUE.

También cabe destacar que en Francia, Italia y Alemania, el proceso a quo fue el control incidental de constitucionalidad (nuestra cuestión de inconstitucionalidad, planteada al TC por el juez ordinario), mientras que en el caso de España se produjo en el contexto de un recurso de amparo. En todos ellos, se marcó una línea interpretativa que ya no se ha abandonado, al considerarse a partir de entonces que el Derecho de la Unión ostenta relevancia constitucional también como Derecho interno de los Estados miembros.

\section{El incipiente "diálogo" entre el Tribunal Europeo de Derechos Humanos y el Tribunal de Justicia de la Unión Europea}

Antes de la entrada en vigor del Tratado de Lisboa, que impone la ratificación del CEDH por parte de la UE (art. 6 TUE), la importante posición adquirida por el CEDH en el acervo comunitario originó que se barajara la posibilidad de que la UE ratificara el CEDH. En un primer momento, el Tribunal de Justicia, en un Dictamen solicitado por el Consejo, manifestó que "en el estado actual del Derecho comunitario ello no era posible" por considerar, entre otras cuestiones, que "la Comunidad no tiene competencia para adherirse al Convenio" ${ }^{35}$.

Dos eran los principales obstáculos que fundamentaron la posición del TJUE. Por una parte, el hecho de que el Convenio estuviera conformado para ser ratificado por Estados, no por organizaciones supranacionales, lo cual implicaba que se tuviera que adaptar el Convenio a esta situación. Por otra, la dificultad de determinar la institución comunitaria competente para tal ratificación al no tener personalidad jurídica la Unión, cosa que ha sido superada por la atribución de personalidad jurídica que efectúa el art. 47 TUE.

En el fondo, se planteaba también el problema de que si la UE se adhería al Convenio, los actos comunitarios podían ser controlados por el Tribunal de Estrasburgo y ello podría crear susceptibilidades con relación a las competencias del Tribunal de Luxemburgo. El Tribunal de Justicia no rechazó de plano la posibilidad futura de una adhesión de la UE al CEDH pero declaró que para ello era necesario modificar el TUE. Tal decisión nada cambió en el contexto de aplicación de los derechos del Convenio por parte del Tribunal de Luxemburgo, quien ha continuado hasta hoy día extrayendo los derechos fundamentales del CEDH y de la jurisprudencia del TEDH, como derechos subjetivos incorporados a principios generales del Derecho Comunitario.

La construcción que el reenvío al CEDH efectúa el art. 6 TUE, tuvo también el efecto de incorporar diversas construcciones interpretativas del Tribunal de Estrasburgo, como órgano de interpretación y aplicación del Convenio, como elementos de interpretación aplicados por el propio Tribunal de Justicia comunitario, y ello aún antes de la entrada en vigor del propio TUE. Por poner unos ejemplos, de entre los más relevantes citaremos, en relación con la utilización del

35 Ver al respecto el Dictamen 2/94 del TJUE, de 28 de marzo de 1996, intitulado “Adhesión de la Comunidad al Convenio para la Protección de los Derechos Humanos y de las Libertades Fundamentales". 
CEDH por parte del TJUE, la invocación del principio de no retroactividad del art. 7 del CEDH en la STJUE Affaire 63/83, del 10 de julio de 1984. También la invocación del derecho de propiedad del Protocolo 1 al CEDH en el Affaire 44/79, del 13 de diciembre de 1979. También la invocación de los arts. 6 y $13 \mathrm{CEDH}$, sobre el derecho al proceso equitativo en el Affaire 222/84, del 15 de mayo de 1986.

Además, acerca de la utilización de la doctrina del TEDH como fuente argumentativa por parte del TJUE hay que decir que éste, en su función jurisdiccional, comprueba tanto si existen sentencias del TEDH relativas al asunto que tenga que dilucidar como si el Tribunal de Estrasburgo no ha intervenido en tales temas. Entre las sentencias más relevantes que utilizan la doctrina del TEDH como fuente expresa podemos señalar el Affaire Comafrica y Dole Fresh Fruit Europe contre la Commission Européenne, de 12 de julio de 2001, donde se cita la STEDH Borgers contra Bélgica, de 30 de octubre de 1991, en relación con el derecho al juicio equitativo del art. $6 \mathrm{CEDH}$; también el Asunto Mannesmannröhren-Werle contre la Commission Européenne, de 20 de febrero de 2001, donde se cita la STEDH Funke, de 25 de febrero de 1993, sobre el derecho a no autoinculparse. Y también se puede citar el Affaire Conseil contre Hautala, del 10 de julio de 2001, en el cual el TJUE señala que no existe doctrina del TEDH aplicable al caso sub iudice porque éste no ha intervenido hasta el momento en un asunto semejante.

A mayor abundamiento, como ya ha sido advertido, la doctrina del TEDH sirve también de soporte argumentativo al mismo TJUE, que en repetidas ocasiones ha citado expresamente al Convenio y al Tribunal de Estrasburgo como fuente de sus fundamentos jurídicos. Así, el TJUE ha considerado que, en el marco del Derecho de la UE, los derechos del Convenio tienen un carácter de verdaderos derechos subjetivos a todos los efectos. En este sentido resulta oportuno destacar algunos puntos. En primer lugar, la invocación del principio de no retroactividad de la ley penal, reconocido en el art. 7 del CEDH e integrado en todos los sistemas jurídicos de los Estados miembros, para no admitir una validación "a posteriori" de medidas nacionales de carácter penal que en el momento de su aplicación no eran compatibles con el Derecho comunitario. En segundo término la invocación del derecho de propiedad del protocolo n. ${ }^{\circ} 1$ al CEDH para pronunciarse sobre el Reglamento del Consejo CEE n. ${ }^{\circ} 1162 / 1976$, art. 2.1 (modificado por el Reg. n. ${ }^{\circ}$ 2776/1987), el cual no aceptaba que se otorgaran más autorizaciones para nuevas plantaciones de viñedos. Y un tercer aspecto consistente en la invocación de los artículos 6 y $3 \mathrm{CEDH}$ y de la tradición constitucional de los Estados miembros para no reconocer valor probatorio a las certificaciones de los órganos del poder ejecutivo que no comportaran un control jurisdiccional.

Es necesario señalar, en este punto, que, si bien no se ha efectuado todavía la ratificación prevista en el art. 6 TUE, el Consejo de Europa, haciéndose eco de la necesidad de adaptar el Convenio para que pueda ser ratificado por la UE, ha adoptado el Protocolo n. ${ }^{\circ}$ 14, que ha entrado en vigor el 1 de junio de 2010, modificando a tales efectos el art. $59 \mathrm{CEDH}$.

También es importante destacar, en el marco del "diálogo" entre ambas Cortes, que tras la reunión habida el 24 de enero de 2011 entre los Presidentes de ambas Cortes, se ha acordado una "Comunicación común" ${ }^{36}$, fundamentada en el principio de subsidiariedad, dentro de la cual destacaré los siguientes puntos:

- Es necesario velar por una estricta coherencia entre los Derechos de la Carta de Derechos Fundamentales de la UE y aquellos reconocidos también en el

36 Communication commune des présidents Costa et Skouris. Accesible en internet: https://curia.europa.eu/jcms/upload/docs/application/pdf/2011-02/cedh cjue francais.pdf. 
CEDH. Podría ser útil, al respecto, una "interpretación paralela".

- En el marco del control de convencionalidad, cuando la UE ratifique el Convenio, la obligatoriedad de agotar los recursos internos obligará a los demandantes a plantear una demanda a los tribunales de la UE, en tanto que jurisdicciones internas, cuando así lo disponga el derecho de la UE respecto de los actos producidos por ésta.

- También en el marco del control de convencionalidad, si se trata de demandas individuales dirigidas contra actos de los Estados miembros de la UE por actos realizados para aplicar el Derecho de la UE, los demandantes deberán primero cerciorarse de la validez del Derecho de la UE mediante una cuestión prejudicial.

Para que ello pueda ser efectivo, la Comunicación reconoce también que será necesario establecer una tipología de casos en los que la competencia del Tribunal de Justicia de la UE esté claramente definida. Además, para no incurrir en dilaciones indebidas, se recomienda que pueda ser aplicable el procedimiento prejudicial de urgencia.

\section{Bibliografía}

Aguilar Calahorro, A. (2011). La primera cuestión prejudicial planteada por el Tribunal Constitucional al Tribunal de Justicia de la Unión Europea - Auto del Tribunal Constitucional 86-2011, de 9 de junio. Revista de Derecho Constitucional Europeo, 16, 471-512.

Arroyo Jiménez, Luis. (2011). Sobre la primera cuestión prejudicial planteada por el Tribunal Constitucional. InDret. Revista para el análisis del Derecho, 4.

Baño León, J. M. (2004). El Tribunal Constitucional, Juez comunitario: Amparo frente al no planteamiento de cuestión prejudicial (STC 58/2004). Revista de Derecho Comunitario Europeo, 18, 465-481.

De Vergottini, G. (2011). Diálogo entre tribunales. Teoría y Realidad Constitucional, 28, 345-359.

Droin, A. (2014). Primera cuestión prejudicial del Tribunal Constitucional Francés al Tribunal de Justicia de la Unión Europea. Revista Jurídica de la Universidad Autónoma de Madrid, 29, 71-83.

Gantier Pérez, R. J. (2016). La efectiva aplicación del Convenio Europeo de Derechos Humanos [trabajo final de máster]. Universidad de Valladolid. Disponible en: https://uvadoc.uva.es/bitstream/10324/16851/1/TFM-D 0056.pdf.

García-Andrade Gómez, J. (2014). La cuestión prejudicial del Tribunal constitucional alemán sobre la decisión OMT. Revista Española de Derecho Europeo, 51, 119-163.

Guastaferro, B. (2013). La Corte costituzionale ed il primo rinvio pregiudiziale in un giudizio di legittimità costituzionale in via incidentale: riflessioni sull'ordinanza n. 207 del 2013. Quaderni costituzionali, 4, 980-982.

López Castillo, A. (2014). "Prejudicializando... Comentario urgente de la primera cuestión prejudicial del TCFA". Teoría y Realidad Constitucional, 33, 315-325.

Macías Castaño, J. M. (2014). La cuestión prejudicial europea y el Tribunal Constitucional. El Asunto Melloni. Barcelona: Atelier.

Novi, C. (2014). Corte costituzionale italiana, Corti costituzionale europee e rinvio preguidiziale: il dialogo diretto con la Corte di giustizia dell'Unione europea e le sue posssibili implicazione a breve e lungo termine. Diritto Pubblico Comparato ed Europeo, 4, 2072- 2103.

Pérez de los Cobos, F. (2015). Conferencia pronunciada en la jornada-seminario 
con motivo de la visita del Presidente del TEDH el 22/05/2015. Disponible en: https://www.tribunalconstitucional.es/ActividadesDocumentos/201505-20-00-00/2015-PonenciaEspaÃ $\pm a . p d f$

Pérez Sola, N. (2015). La defensa convencional de los derechos en España. ¿Es posible el diálogo entre tribunales? Madrid: INAP.

Ripoll Carulla, S. (2007). Incidencia en la jurisprudencia del TC de las sentencias del TEDH que declaran la vulneración por España del CEDH". Revista Española de Derecho Constitucional, 79, 309-346.

Rousseau, D. (2013). "L'intégration du Conseil Constitutionnel au système jurisdictionnel européen". Gazette du Palais, 125-127, 13-16.

Ruiz Miguel, C. (1998). Las sentencias del Tribunal Europeo de Derechos Humanos: su ejecución desde la perspectiva del derecho constitucional comparado y español. En VV.AA. V Congreso Iberoamericano de Derecho Constitucional (pp. 811-846). México: UNAM.

Sarmiento Ramírez-Escudero, D. (2015). La sentencia Gauwailer (C-62/14) del Tribunal de Justicia de la Unión Europea sobre el programa de compra de deuda pública del Banco Central Europeo. Actualidad Jurídica Uría Menéndez, 41, 101-105. 